\title{
Urgences
}

\section{Pour te dire}

\section{Jean Cossette}

Numéro 2, 3e trimestre 1981

URI : https://id.erudit.org/iderudit/025032ar

DOI : https://doi.org/10.7202/025032ar

Aller au sommaire du numéro

Éditeur(s)

Urgences

ISSN

0226-9554 (imprimé)

1927-3924 (numérique)

Découvrir la revue

Citer ce document

Cossette, J. (1981). Pour te dire. Urgences, (2), 71-76.

https://doi.org/10.7202/025032ar

Ce document est protégé par la loi sur le droit d'auteur. L'utilisation des services d'Érudit (y compris la reproduction) est assujettie à sa politique d'utilisation que vous pouvez consulter en ligne.

https://apropos.erudit.org/fr/usagers/politique-dutilisation/ 
JEAN COSSETTE 
POUR TE DIRE

Les tourments qui nous assaillent parfois

à l'orée de nos solitudes partagées

Les ondes de la mort et du venin cafardeux sur nos corps nus et reposés

Le temps qui s'en mêle et l'avance des siècles et l'arrêt de nous

à bout d'étreintes magnifiques

dans l'envol majestueux de nos soupirs mêlés

Le sang qui marie nos complaintes silencieuses L'éveil des yeux sur nos tambours de chair La soif de ne plus finir de ne plus mourir tellement nous sommes deux sous les toits des villes défuntes et ressuscitées sur les fleuves transcendants du désir vers les cimes éternelles blanches et sereines des nuages étrangers

Dans nos bras s'agitent des sanglots se lèvent des soleils enivrés

se larguent des voiles millénaires

Ces heures à chercher la vérité ailleurs qu'en nos tabernacles

Ces gouffres sans fin pour ne pas se perdre

L'attente de rien

L'attente de tout

L'attente de nous alanguis et muets 
Tes mains que je cherche au bout de mes doigts pour ne pas oublier ta présence transparente Tes yeux dans le noir et ton front tourmenté quand je m'évade en toi pour me perdre consciemment

Le rêve qui nous appelle à lui du fond de ses espoirs maquillés

L'envers des matins à se chercher encore et encore Le jour qui descend chercher la nuit

Cette nuit si blanche dans son lit d'humides soupirs

T'emmener loin très loin

là où la terre se repose de ses secousses orgasmiques dans l'espace secret de nos quiétudes émerveillées 


\section{GRISAILLE D'EXISTENCE}

L'ombre coule des formes absentes sur l'étang cafard Tous les oiseaux de glace se sont donné des espaces à revendre

Dans le ciel neutre s'enfonce un oeil crevé et les nuages hissent des pavillons vaincus

Plus de jeux dans l'air!

On a reposé nos mains sur les falaises abruptes de nos corps refroidis

L'heure a fermé boutique bien avant la tombée du jour

Immobiles à se pourfendre le coeur nous respirons à peine de peur de nous entendre vivre 


\section{NEF ASTRALE}

Table découverte où je presse des doigts dans l'attente exaspérée du médium coulant à l'abandon de toi-même respirant à peine sinistrement au banc de neige à la tourmente empoudrée

Comme tu m'attendais

L'Espéra et Sophiène

à bras tendus comme pour manger la soif

à cou tiré vaguement sur le suif passible ou paisible nul ne le sait car autant s'apprendre des mesures en voyage ou à l'assaut des portes closes

Chagrine-moi d'abord que je te vois pleurer Exorcise-moi ensuite à l'atelier des souvenances Equilibre ton sein droit Verse la lumière rose à l'orée d'un visage clos

Parce que la semaine s'étourdit d'ambre quotidien l'homme se dessèche peu à peu

Dans l'humidité astreignante des oublis féconds et alors que l'inconscience se reflète dans une glace traître à souhait le vague tourment s'amène vase en avant à l'assaut des provenances inconnues 
Juge-moi

Justicia Belfémur

n'attends pas que je m'évade

car l'espace-matin m'attend

et tu connais ma soif de départs

mon avidité des champs stratostiphiés

mon entendement extraverti à l'ouverture du destin

À la pluie

Jette les bas-fonds de tes sommeils

Porte vers les cabines en mer tes bras démesurés

et abstiens-toi

des lames vengeresses

ce-ll-es-qui-courent-à-la-sur-face-froi-de-des-mers

Oui

les mers d'anciennes magies engouffrantes

les mers soyeuses comme des plantes malades

Ombragée tu es

à la porte des cathédrales gémissantes

quand novembre se lance en bas des clochers

à la désespérante lumière des nefs matinales. 